
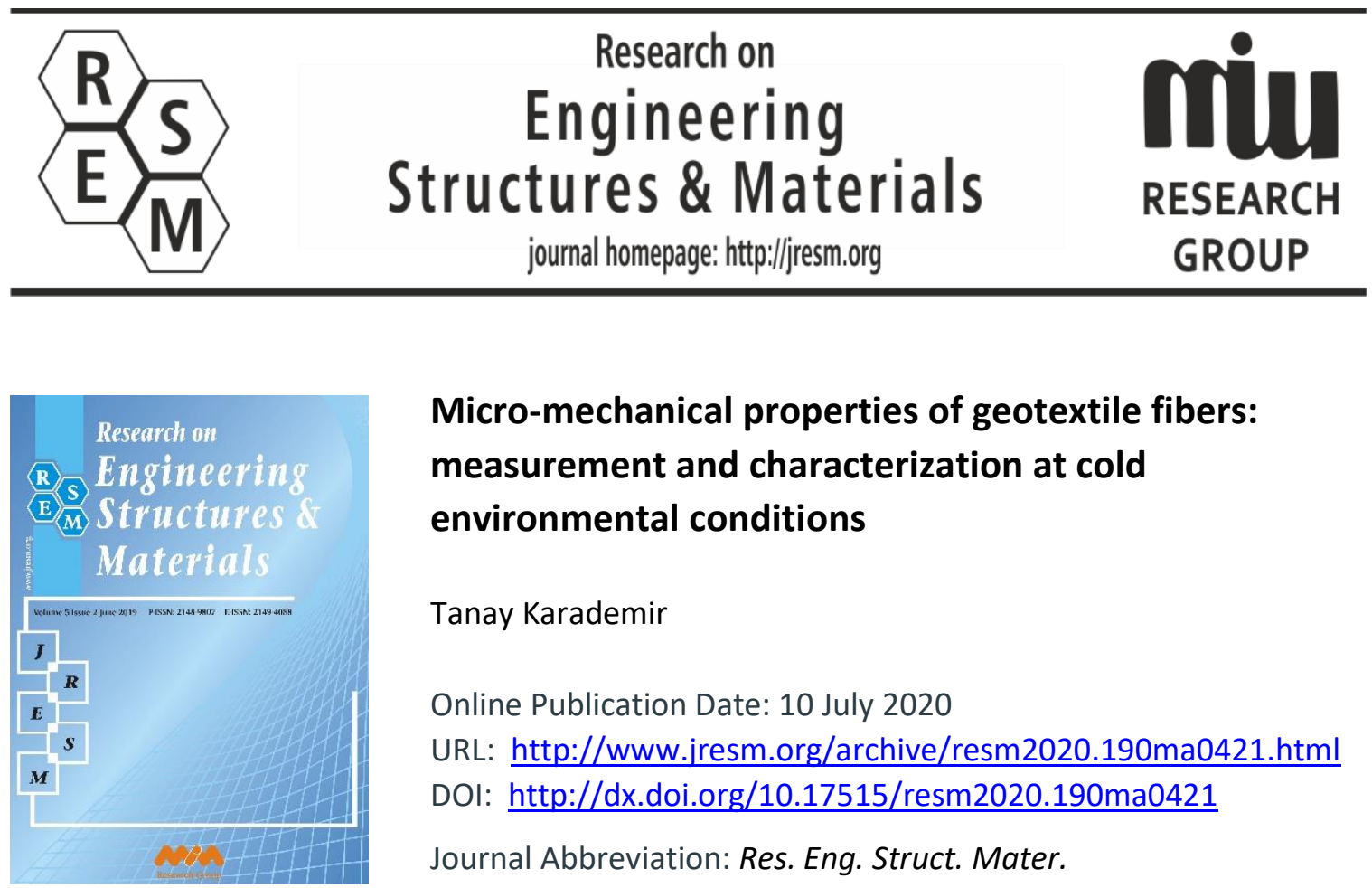

\title{
Micro-mechanical properties of geotextile fibers: measurement and characterization at cold environmental conditions
}

Tanay Karademir

Online Publication Date: 10 July 2020

URL: http://www.jresm.org/archive/resm2020.190ma0421.html

DOI: http://dx.doi.org/10.17515/resm2020.190ma0421

Journal Abbreviation: Res. Eng. Struct. Mater.

\section{To cite this article}

Karademir T. Micro-mechanical properties of geotextile fibers: measurement and characterization at cold environmental conditions. Res. Eng. Struct. Mater., 2021; 7(1): $97-$ 120.

\section{Disclaimer}

All the opinions and statements expressed in the papers are on the responsibility of author(s) and are not to be regarded as those of the journal of Research on Engineering Structures and Materials (RESM) organization or related parties. The publishers make no warranty, explicit or implied, or make any representation with respect to the contents of any article will be complete or accurate or up to date. The accuracy of any instructions, equations, or other information should be independently verified. The publisher and related parties shall not be liable for any loss, actions, claims, proceedings, demand or costs or damages whatsoever or howsoever caused arising directly or indirectly in connection with use of the information given in the journal or related means.

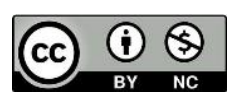

Published articles are freely available to users under the terms of Creative Commons Attribution - NonCommercial 4.0 International Public License, as currently displayed at here (the "CC BY - NC"). 


\section{Research on Engineering Structures \& Materials}

journal homepage: http://jresm.org

Research Article

\section{Micro-mechanical properties of geotextile fibers: measurement and characterization at cold environmental conditions}

Tanay Karademir

Department of Civil Engineering, Istanbul Bilgi University, Istanbul, Turkey

\begin{tabular}{|c|c|}
\hline Article Info & Abstract \\
\hline $\begin{array}{l}\text { Keywords: } \\
\text { Polypropylene Fibers; } \\
\text { Geotextiles; } \\
\text { Mechanical Properties; } \\
\text { Ambient Conditions; } \\
\text { Cold Temperatures }\end{array}$ & $\begin{array}{l}\text { One of the most important properties of a fabric (geotextile) and also one of the } \\
\text { focus areas of the current research study is its tensile strength, and thus, } \\
\text { mechanical properties (modulus, resilience, strength, toughness). To this end, } \\
\text { the mechanical properties of the geotextiles must properly be evaluated at the } \\
\text { "macro-scale" as well as at the "micro-scale" as they are fibrous synthetic } \\
\text { materials including polymeric fibers as well as significant volume of void space. } \\
\text { As being a polymer, the mechanical behavior of the geotextile micro-fibers is } \\
\text { highly dependent on the ambient conditions including particularly the } \\
\text { temperature. In light of this, the tensile behavior of geotextile single micro-fibers } \\
\text { was characterized by performing micro-mechanical tensile tests at "micro-scale" } \\
\text { level at different cold temperature conditions using Dynamic Thermo- } \\
\text { Mechanical Analyzer (DMA) to measure the developed "micro-scale" tensile } \\
\text { stress - strain behavior of geotextile micro-fibers. The results examined from the } \\
\text { influence of micro-mechanical properties of polymeric fibers on the observed } \\
\text { temperature dependent stress-strain curve were used to determine the modulus } \\
\text { of elasticity (E), modulus of resilience (UR), ultimate tensile strength (Tmax), } \\
\text { amount of plastic strain ( } \varepsilon_{\mathrm{p}} \text { ), toughness (UT), rupture strength ( } \mathrm{T} \text { R) for the } \\
\text { polypropylene (PP) micro-fiber of needle-punched nonwoven (NPNW) } \\
\text { geotextile and the variation in those important mechanical properties with a } \\
\text { change in ambient temperature conditions. The experimental results show that } \\
\text { the mechanical properties of the PP fibers do not remain constant within the } \\
\text { common range of cold temperatures (-10 }{ }^{\circ} \mathrm{C}-21{ }^{\circ} \mathrm{C} \text { ) found in typical civil } \\
\text { engineering applications such that the temperature change was found to be an } \\
\text { important factor affecting the PP fiber micro-mechanical properties such as } \\
\text { modulus, strength, toughness and plastic elongation. Therefore, the test results } \\
\text { provide an index of behavior at "micro-scale" level for the polymeric geotextile } \\
\text { single fibers at cold temperature conditions. }\end{array}$ \\
\hline
\end{tabular}

(C) 2021 MIM Research Group. All rights reserved.

\section{Introduction and Background}

Temperature has a significant effect on the mechanical properties of polymers, such as modulus, tensile strength, toughness and hardness. Polymers soften and eventually flow as they are heated while they harden when cooled $[1,2]$. Therefore, it is important to know the limiting temperatures at which polymer components can still be loaded with moderate deformations [3]. One of the most important properties of a fabric (geotextile) and also one of the focus areas of the current research study is its tensile strength, and thus, mechanical properties (modulus, resilience, strength, toughness). Most geotextile applications have been developed by relying on those engineering properties [4]. This is attributed to the fact that many geosynthetic applications using geotextiles are designed to complement the relatively low tensile capacity of soils [5]. To this end, tensile stress-strain (or: tensile force-displacement) test that is one of the common mechanical test types extensively used for polymeric materials (geotextiles) will comprehensively be examined in the paper.

Corresponding author: tanay.karademir@bilgi.edu.tr

https://orcid.org/0000-0002-9689-2140;

DOI: $\underline{\text { http://dx.doi.org/10.17515/resm2020.190ma0421 }}$

Res. Eng. Struct. Mat. Vol. 7 Iss. 1 (2021) 97-120 
Temperature has a significant effect on tensile properties of polymers [6, 7]. Since polymers are anisotropic materials and highly sensitive to both temperature change and strain rate $[3,8]$. As temperature decreases in a polymeric material, a gradual contraction of the material occurs, resulting in less free volume as well as strengthening of the bonding forces which form the polymer structure and constitute the network of polymer chains holding the material together $[3,9]$. Further, the tensile behavior of a polymer is strongly related to the state of the material which is dependent on its temperature. Polymers (Oriented Crystal Fiber, Glassy) are brittle at the lowest temperatures. As the temperature decreases, they become more "tough", until they reach brittle-ductile transition below which polymers become sufficiently brittle that they can exhibit rupture (break) at relatively small strains. Further decrease in temperature leads to a glassy-like behavior [8, 10]. As the operating temperature range (typically $-10{ }^{\circ} \mathrm{C}$ to $40{ }^{\circ} \mathrm{C}$ ) in the field for PP geotextile is limited to temperatures much lower than $\mathrm{T}_{\mathrm{m}}$ and higher than $\mathrm{T}_{\mathrm{g}}$, geotextile single fibers manufactured from this polymeric material is expected to exhibit temperature dependent "stiffness" and "ductile elasto-plastic" tensile behavior [6, 9]. Moreover, the type of behavior a polymeric material shows (brittle versus ductile) when tested depends on the strain rate of extension in tensile tests. For example, if extremely high strain rates are used, a polymer can exhibit brittle behavior at almost any temperature [4, 7]. Since geotextiles are made from polymeric materials, it is well known that their behavior can be affected by test conditioning such as ambient temperature, and the rate of extension or contraction in tension or compression tests, respectively such that there is an important aspect of fibrous materials (e.g. geotextiles) which must always be considered when fabrics are tested in tension mode.

In the earlier research works, the geotextiles being a very common polymer-based material utilized in a wide range of infrastructural applications were tested and the mechanical properties were characterized at macro scale only. On the other hand, the geotextile is a nonwoven fibrous material (fabric) that contains micro-fibers and significant amount of void (pore) space. For this reason, macro-scale characterization and response observed in the past could be deemed as incomplete since unable to provide a comprehensive understanding and sufficient insight to the micro-mechanical properties of geotextile fibers at micro-state and their measurement and characterization at cold environmental conditions (cold temperatures). To this end, the research work presented in the paper will provide a different perspective onto the topic in light of the reasons discussed in detail as follows: The geotextiles can exhibit different tensile stress-strain behavior as well as show favorable versus adverse response to varied test conditions such as temperature and strain rate variations when tested at the "macro-scale" level versus when tested at the "microscale" level. This is due to the heterogeneous internal structural formation of the fibrous materials (geotextiles) such that the total deformation under extension or contraction loading is the cumulative result of fiber deformation and internal structural rearrangement of the geotextile for which the initial elasto-plastic type deformation is strongly temperature and strain rate dependent, while the long-term rearrangement type deformation is not $[11,12]$.

\section{Characterization of Micro-Mechanical Properties of Geotextile Fibers}

\subsection{Fabric Characteristics used in Testing Program}

The tested micro-fibers were extracted from a staple fiber polypropylene (PP) needlepunched nonwoven (NPNW) type geotextile. NPNW geotextiles consist of spatially curved fibers that are often assumed to be randomly oriented and isotropically distributed [12, 13]. 


\subsection{Experimental Device: Dynamic Thermo-Mechanical Analyzer (DMA)}

Dynamic Thermo-Mechanical Analyzer (DMA) (Figure 1) was first used to measure micromechanical properties (tensile behavior or the developed "micro-scale" stress-strain response) of geotextile fibers.

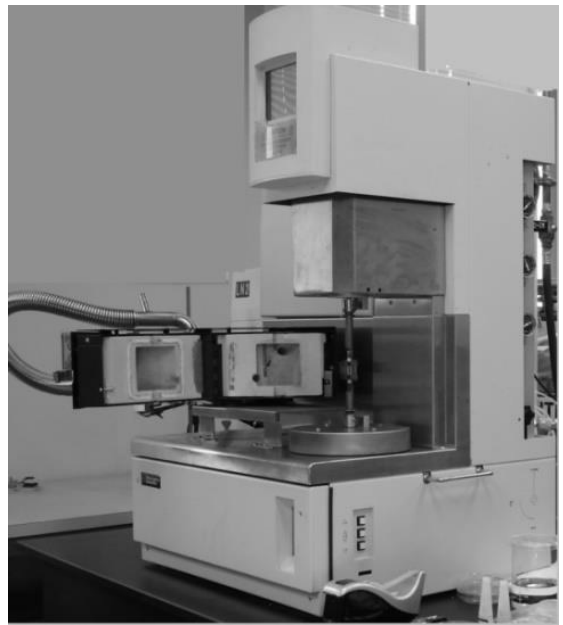

Fig. 1 Computer Automated Dynamic Thermo-Mechanical Analyzer (Entire System)

\subsection{Consistency and Accuracy of Measurements}

Among several modes of operations (e.g. Multi-Frequency, Multi-Stress-Strain, Creep Stress-Relaxation, Isostrain) (Figure 2) that the DMA provides, the Controlled Strain Rate mode (Figure $2 \mathrm{~b}$ ) was used to measure tensile properties and to investigate the development of tensile stress versus strain relationships of single geotextile fibers at different cold temperatures. In this mode of operation, strain is ramped at a constant rate while the temperature is held constant. As such, the micro-scale tests were conducted at constant rate of elongation at micro-state (controlled strain rate mode: Figure 3) over the range of cold temperatures from $-10{ }^{\circ} \mathrm{C}$ to $21^{\circ} \mathrm{C}$ with $5{ }^{\circ} \mathrm{C}$ increments between different test temperatures to observe the repeatability of the developed tensile force-extension behavior as well as to see the reproducibility of fiber tensile strength response at every test temperature.

In particular, Figure 3 demonstrates that the experimental set-up has high capability and robust performance in applying accurate strain controlled extensional tension on microfibers during the entire course of the tests from the initiation to the end at all test temperatures even at cold ambient temperature condition of $-10^{\circ} \mathrm{C}$. Further, as seen in Figure 3 that the tensile tests for the entire range of cold test temperatures performed using Controlled Strain Mode in which Strain over Stress Ratio increases linearly with a constant rate with respect to time (Figure $2 \mathrm{~b}$ ) among the alternative testing and characterization modes as shown in Figure 2 verifies that the system has advanced as well as robust control and accurate, consistent measurements on the whole tested micro-fiber specimens during the experiments at all cold test temperatures. Since, the four different tests at each test temperature demonstrates similar response and consistent behavior which confirms the reproducibility of micro-fiber tensile strength at every test temperature and the repeatability of the developed tensile force - extension behavior for the tested micro-fibers (Figure 3). 


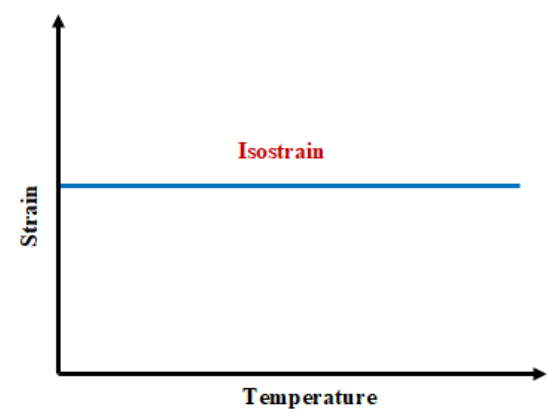

(a)

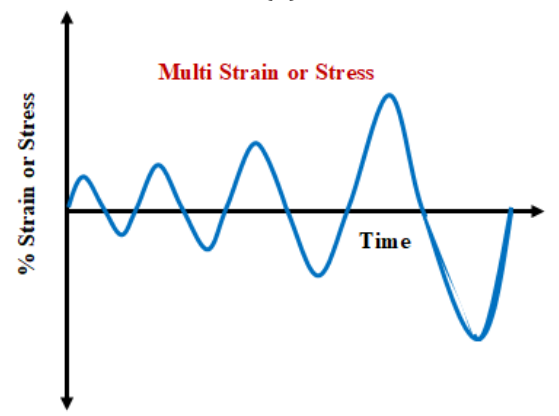

(c)

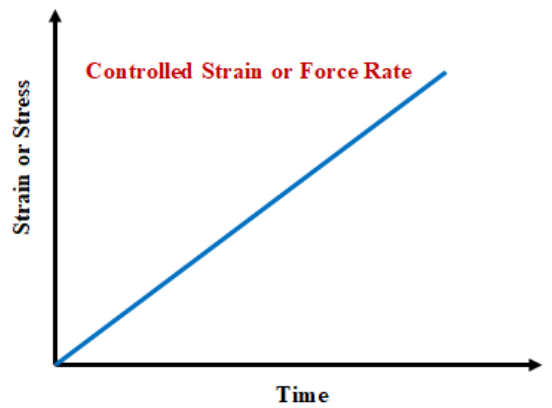

(b)

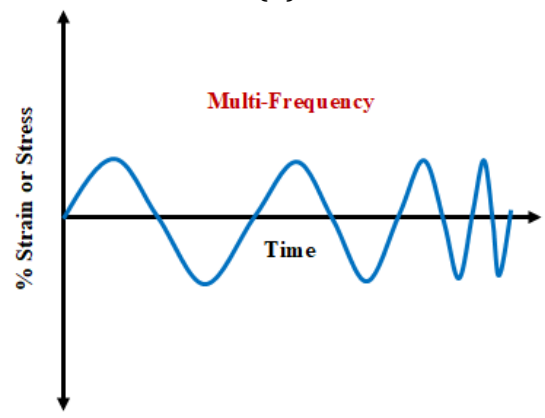

(d)

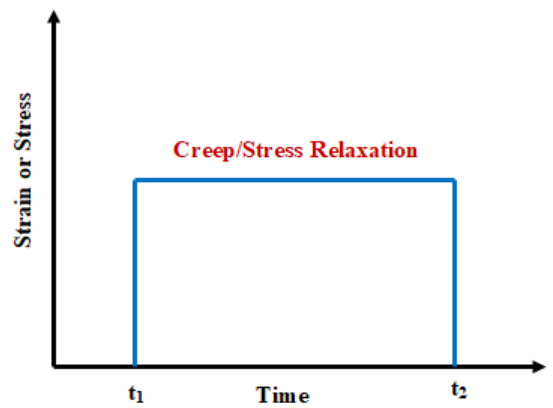

(e)

Fig. 2 Different Modes of Micro-Mechanical Testing and Characterization 


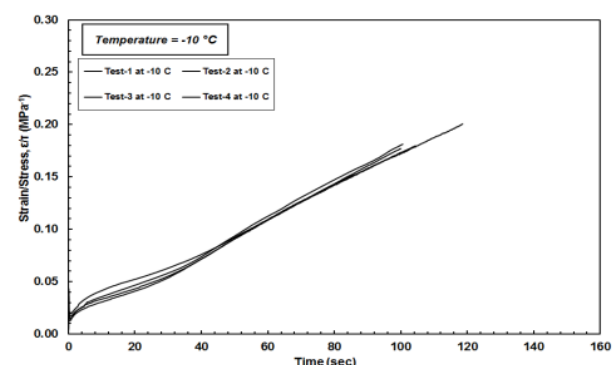

(a)

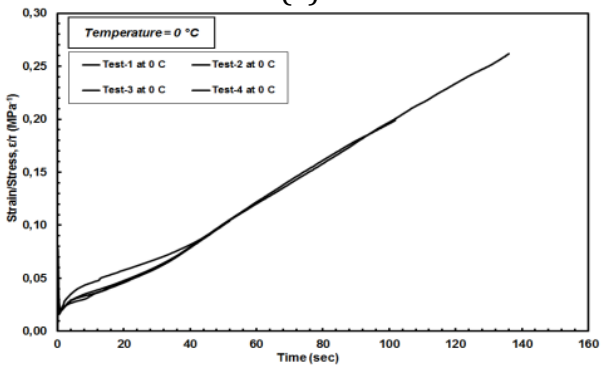

(c)

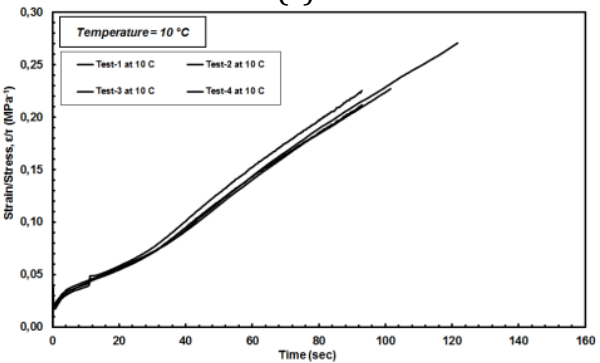

(e)

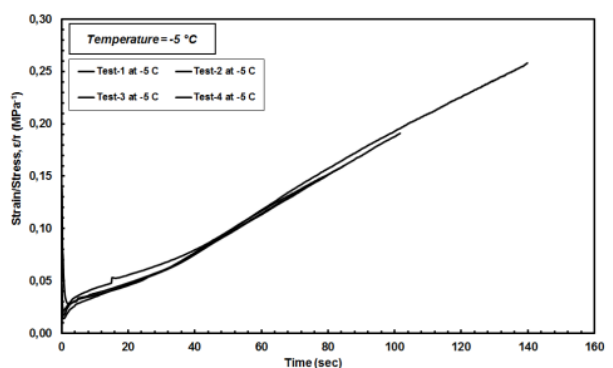

(b)

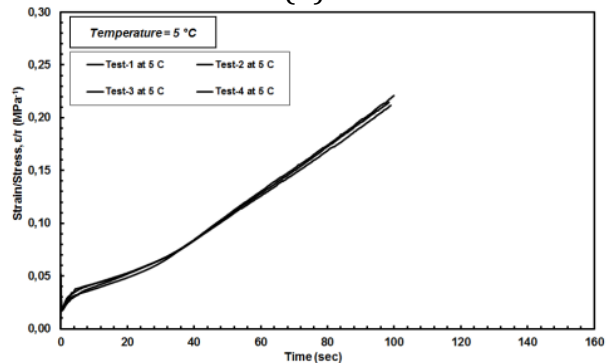

(d)

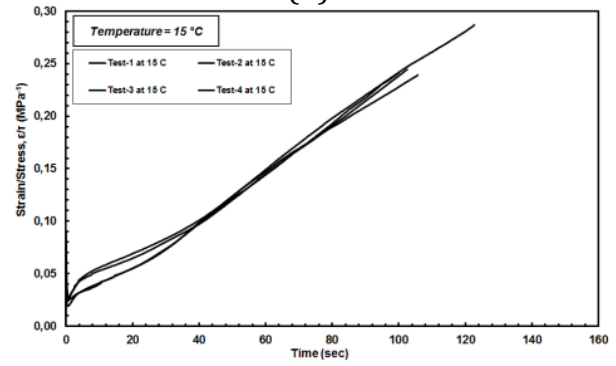

(f)

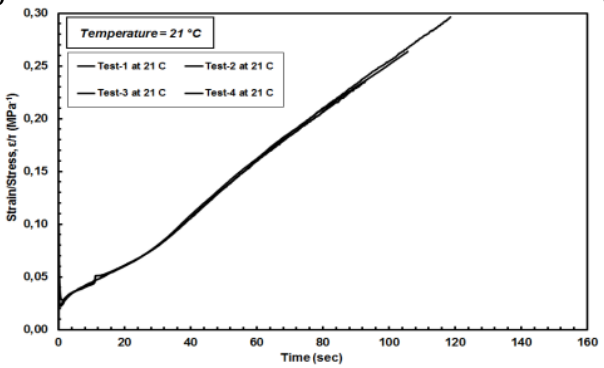

(g)

Fig. 3 Controlled Strain Rate Mode of Testing for Micro-Fibers at Different Ambient Conditions

\subsection{Characterization Technique: Test Method, Sample Preparation and Experimental Procedures}

The micro-fiber specimens (Figure 4) tested to failure using a constant-rate-of uniaxial extension (CRE) type tensile testing of a predetermined gage length and rate of extension at different cold temperatures were extracted from geotextile samples selected randomly from the big roll of the textile fabric. After preparation, the fiber test specimens were placed and conditioned between two smooth clamp fixtures (with flat jaws for gripping the fiber specimens) of the Dynamic-Thermo-Mechanical Analyzer (DMA). The distance 
between the clamps was adjusted to obtain the selected nominal gage length of $12.5 \mathrm{~mm}$. The fiber which was glued on the paper tab was gripped with a set of stationary jaws by removing slack without stretching the specimen and then, the axial alignment of the fiber must be ensured by carefully controlling the paper tab and the fiber tension kit. After moving the grips to ensure that the specimen was axially aligned straight, the paper tab was cut gently at the middle points of either side. Before initiating the experiment to measure tensile properties and to investigate the development of tensile force versus elongation curve of PP fibers at cold temperature conditions, the oven was closed and the temperature was decreased down to the target test temperature through the controller software of the system. Subsequently, the test was initiated and the PP fiber specimens were stretched in tension and ruptured using a constant-rate-of extension (CRE) type tensile test in which the rate of extension (extension speed) was set as a constant value of $0.125 \mathrm{~mm} / \mathrm{s}$ for fiber specimens having an average diameter of $0.035 \mathrm{~mm}(35 \mu \mathrm{m})$ to provide proper rate of elongation for the gage length (net measurement length of the fiber) of $12.5 \mathrm{~mm}$ selected. This strain rate was determined based on initial specimen length, $\mathrm{L}$; $[\mathrm{d} \varepsilon / \mathrm{dt}=(\mathrm{L} / 100)]$ and intentionally used to observe the entire deformation behavior consisting of i) elastic elongation; and ii) inelastic deformation of fiber polymeric materials under tension until the rupture takes place. After breaking the specimen, the tension clamp was returned to its original position (starting condition) and all remains of the failed specimen were removed from the clamp faces.

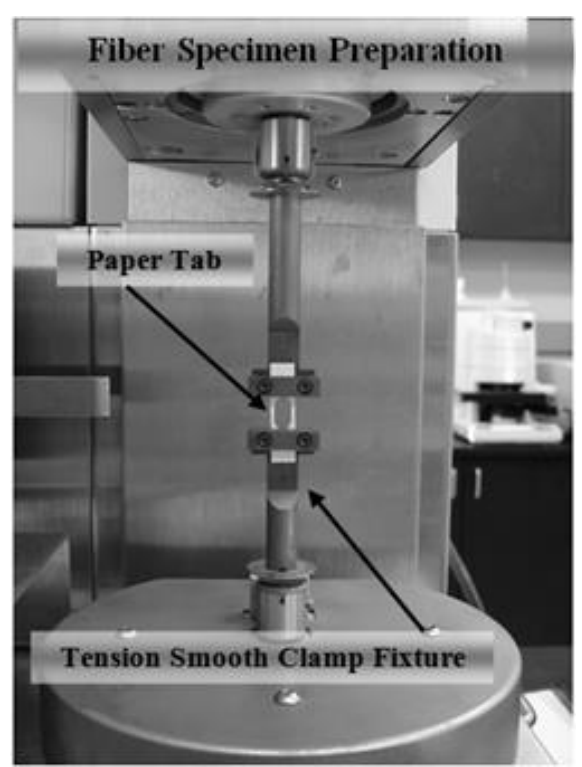

(a)

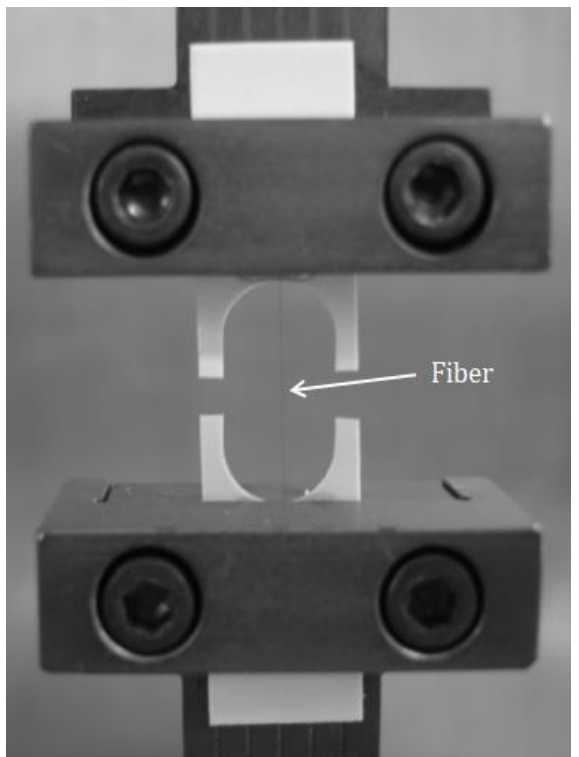

(b)

Fig. 4 The PP Micro-Fiber Test Specimen Placement and Conditioning

The area correction for the tested single geotextile specimens during the experiments were automatically performed by the controller software of the DMA as follows. After moving the grips to ensure that the specimen was axially aligned straight, the exact diameter of the specimen was measured and the value of which was entered into controller program so that the program during elongation was able to automatically compute the tensile stress by using the current cross-sectional area of the specimen detected by the digital camera system during extension of the specimen and comparing this value with the initial crosssectional area. Therefore, the tensile stresses measured were the corrected values based 
on elongation of the specimen and the resulting contraction occurred in the area detected by the integrated camera system.

\section{Micro-Scale Mechanical Behavior and Response of Fibers}

\subsection{Introduction and Scope}

The tensile stress - strain curves at different cold temperatures for polypropylene (PP) micro-fibers are presented in Figure 5. The tensional elongation behavior of micro-fibers within the entire range of ambient temperatures tested $\left(-10{ }^{\circ} \mathrm{C}\right.$ to $\left.21{ }^{\circ} \mathrm{C}\right)$ comprised of elasto-and-predominantly-plastic response comparing the amount of strain exhibited during the course of plastic elongation relative to that of displayed throughout elastic elongation (Figure 5).

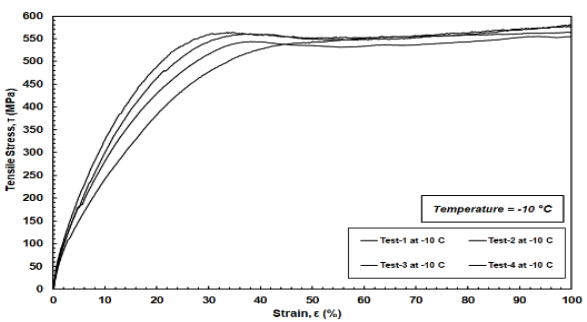

(a)

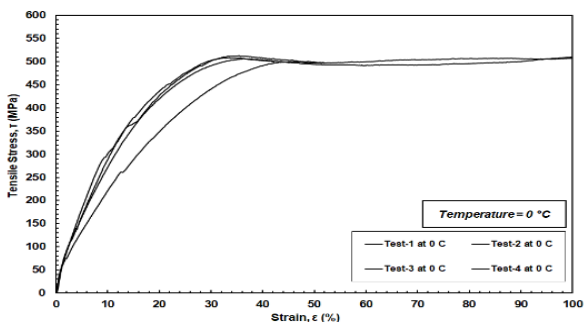

(c)

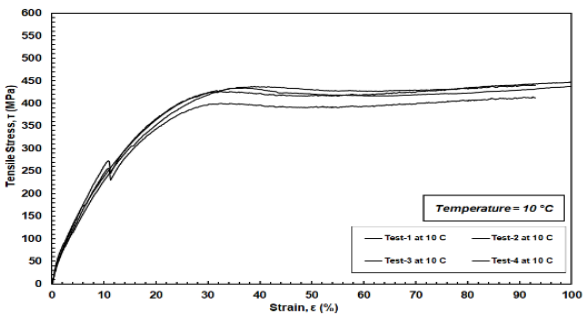

(e)

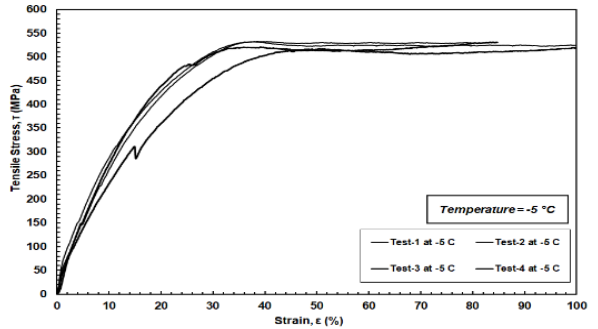

(b)

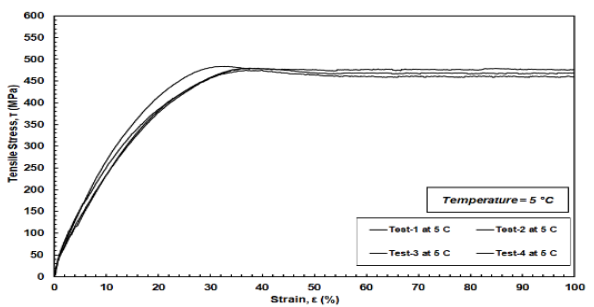

(d)

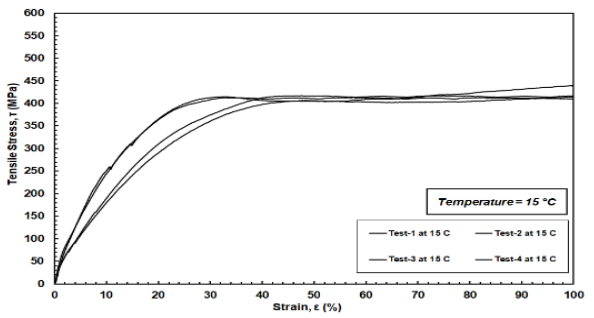

(f)

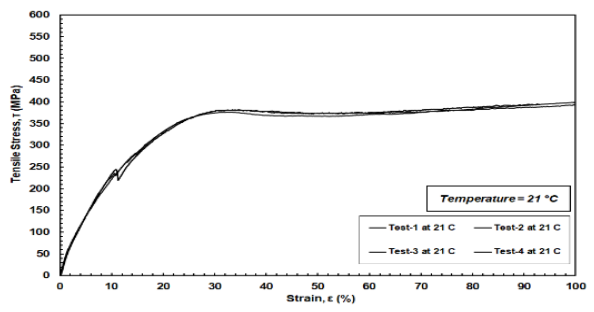

(g)

Fig. 5 Tensile Stress - Strain Curves at Different Temperatures for Polypropylene Micro-Fibers tested at Constant Rate of Elongation at Micro-State 
Moreover, the tensile stress versus axial strain curves at different temperatures demonstrate that there occurs a dramatic (very sharp) increase in tensile stress within a small strain (elongation) of the fiber, and thereafter, the rate of increase in tensile stress becomes gradual at a slower rate prior to yielding transforming to plastic response after elastic elongation. Furthermore, as seen in Figure 5, during plastic elongation, tensile stress remained approximately constant although the elongation of the specimen continued, however, the specimens were not able to withstand additional tensile stress. Based on observations made on post-test micro-fiber specimens after the experiments were completed, it was seen that the failure (rupture point) took place at different locations of the sample gauge length with some being close to the middle of the specimen, whereas, others were closer to either end (up or down) where the tension break rupture occurred in the upper or lower portion of the fiber specimens.

\subsection{Shape and Development of Stress versus Strain/Stress Curves at Different Temperatures and Elasto-Perfectly-Plastic Behavior}

Micro-mechanical uniaxial tensile tests on the micro-fibers performed under a "constant rate" of extension loading at test temperatures ranging from $-10{ }^{\circ} \mathrm{C}$ up to $21^{\circ} \mathrm{C}$ with $5{ }^{\circ} \mathrm{C}$ increments between different test temperatures displayed predominantly inelastic response exhibited over a relatively large strain intervals as compared to that of elastic response mobilized over a very limited strain intervals (Figure 6). The shapes of stress versus strain/stress curves for all the tests performed on micro-fiber specimens at various cold temperatures were in good agreement, and indicated that plastic elongation behavior (nonlinear elasto-perfectly plastic form) occurs in polypropylene fibers under tensile load prior to failure or rupture of the fibers. The strain over stress ratio at the onset of the tests reads about $0.1 \mathrm{MPa}^{-1}$, and then, with an initial slight (insubstantial) increase in tensile stress, this ratio reduces to $0.02 \mathrm{MPa}^{-1}$ within a very small time interval of measurement. Later, stress increases linearly and dramatically with respect to strain over stress ratio at a constant positive slope $\left(\right.$ Slope $=[$ Stress $/($ Strain $/$ Stress $)]=$ Stress $^{2} /$ Strain $)$ within a very short time interval of measurements which indicates that, at this stage of the tensile tests, the square of stress is directly proportional to strain through a linear (1st order) relationship. Finally, beyond a strain over stress ratio of $0.07-0.08 \mathrm{MPa}^{-1}$, the stress remains approximately constant displaying a slope of zero $\left(\right.$ Slope $=$ Stress $^{2} /$ Strain $)$ demonstrating that the tensile stress measured for the rest of the test progress remains more or less constant that is an indication of perfectly plastic behavior as such the strain increases at a constant rate of elongation implying true plastic behavior of micro-fibers prior to rupture at about $0.25 \mathrm{MPa}^{-1}$ strain over stress ratio. Although the elastic stage lasts within a relatively short interval of the strain/stress of $0.06 \mathrm{MPa}^{-1}$, the plastic stage progresses at a much larger interval of the strain/stress of $0.17 \mathrm{MPa}^{-1}$. To this end, it is seen that the elongation of micro-fibers under tension over the entire range of test temperatures from $-10{ }^{\circ} \mathrm{C}$ to $21{ }^{\circ} \mathrm{C}$ is predominantly comprised of permanent plastic straining along with a minor and limited amount of temporary elastic deformation. 


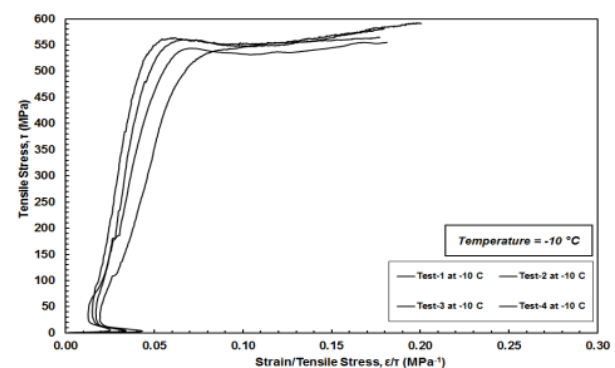

(a)

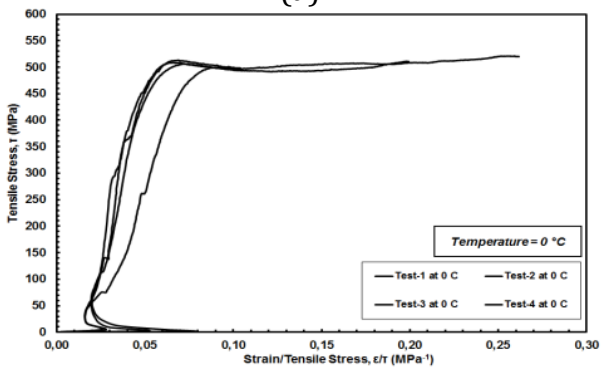

(c)

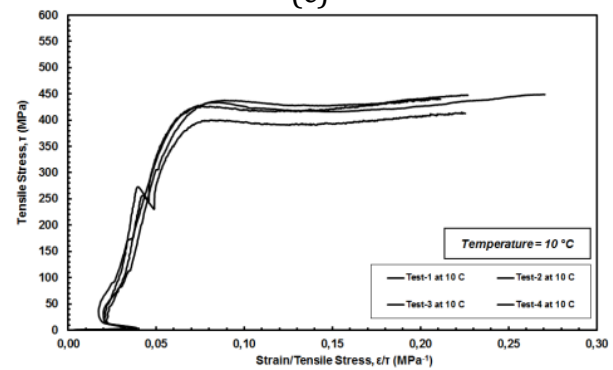

(e)

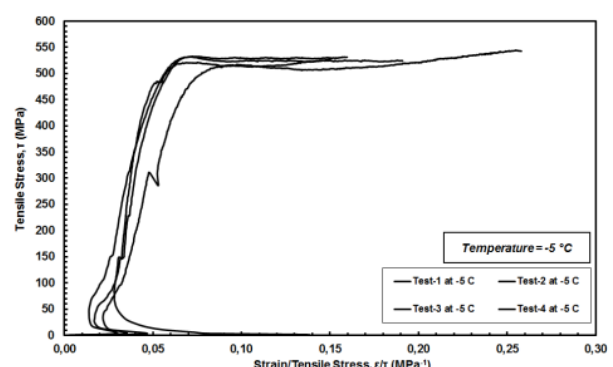

(b)

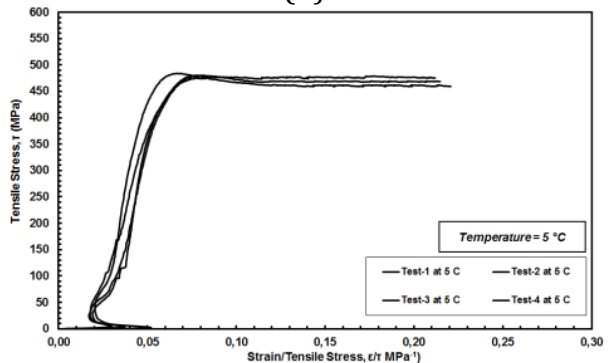

(d)

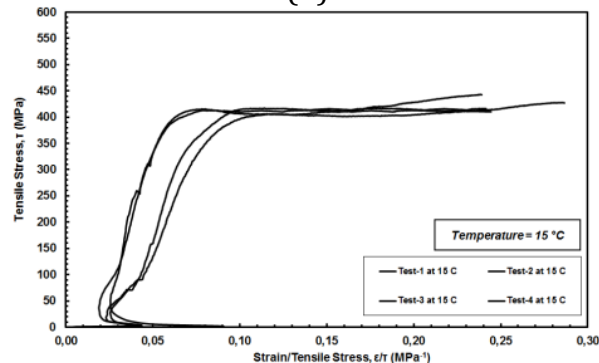

(f)

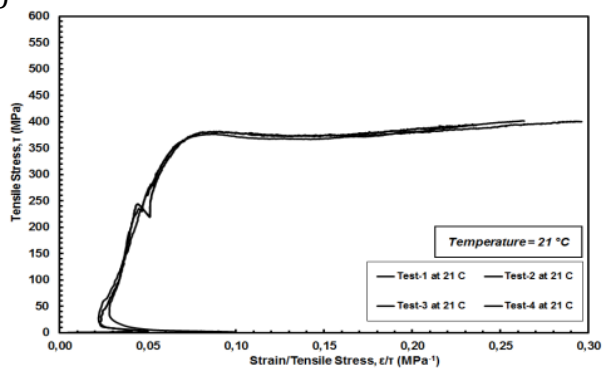

(g)

Fig. 6 Tensile Stress - Strain/Stress Curves at Different Ambient Temperatures

Further, the tensile stress versus strain/stress curves at different cold temperatures presented in Figure 6 are descriptive and provide an opportunity in illustration for a detailed view and helps us see obviously the different stages of elasto-perfectly-plastic behavior and fiber yielding stage in demonstrating the details of transformation of the behavior from elastic to plastic. Moreover, Figures 5 and 6 verify the accuracy and consistency of the measurements for the mechanical properties of the micro-fibers tested at different cold temperatures from the proximity of the curves in the replicate tests at the same test temperature. 


\subsection{Assessment of Ductility and Brittleness for the Material Tested}

There is an apparent trend which can be observed in the series of graphs in both Figures 5 and 6 of the tensile stress versus strain and/or strain/stress failure envelopes, respectively, for polypropylene fiber specimens growing with a decrease in temperature such that the size of the area under the curve enlarges which is an indication of greater energy absorbed by the fiber during tensile deformation under the load. As such, for the tested polymeric fibers, the tensile stress - strain curves from colder temperature tests fall outside of the failure envelope of that defined by the warmer temperature tests. This variation in tensile stress versus strain response shows the influence of temperature on the PP micro-fibers at micro-state. Furthermore, the fibers are highly ductile with majority of the fibers experiencing a large amount of plastic deformation before rupture (Figures 5 and 6). Brittle tension rupture for the specimens was not observed for the temperature range tested $\left(-10^{\circ} \mathrm{C}\right.$ to $\left.21^{\circ} \mathrm{C}\right)$. Brittle failure modes generally occur under glass transition temperature $\left(\mathrm{T}_{\mathrm{g}}\right)$ of polymeric material as the nature of bonding between the molecules of polymers is based on ambient temperature.

Furthermore, Figure 7 demonstrates stress over strain ratio with respect to strain in the tensile tests at different cold temperatures. The purposeful use and illustrative explanation of Figure 7 is such that the stress to strain ratio, at all test temperatures, escalates very fast within only $1 \%$ strain of elongation, and arrives to a very sharp point peak (indication of elastic elongation), and thereafter, drops off exponentially, and finally reaches to approximately constant values at about $40 \%$ strain of elongation after which remains asymptotically until fiber rupture. The slope of the curves in Figure 7 represents the proportion of tensile stress to the square of strain $($ Slope $=[\{$ Stress $/$ Strain $\} /$ Strain $]=$ $\left[\right.$ Stress $\left.\left./(\text { Strain })^{2}\right]\right)$. A very rapid increase in the stress to strain ratio at the onset of the tests within only $1 \%$ axial strain with increasing nonlinear slope of the curves at this stage demonstrates that the measured tensile stress ramps up very quickly at a much higher rate than the $\left(\operatorname{strain}^{2}\right)$. This is attributed to enhanced resilience of the polypropylene microfibers exhibited at elastic stage of elongation under the application of tensile elongation instantly within very small range of longitudinal strains less than $2 \%$ that testifies the development of immediate elastic response as soon as the fiber has been tensioned extensionally where the linear increase of stress over strain ratio at a constant rate with respect to axial strain verifies and demonstrates the development of elastic response. Thereafter, the exponential decrease after the "sharp point peak" displayed in the curves in Figure 7 reveals that the rate of increase in tensile stress at elastic stage begins to decrease gradually indicating the behavior is transforming from elastic to plastic nature by passing through a transition zone up until $40 \%$ of tensile elongation. This stage of the tensile response was portrayed as a logarithmic increase behavior with a decreasing rate of increase in the tensile stress versus axial strain curves shown in Figure 5 as a mid-phase in between elastic and plastic stages of the tests. Additionally, a relatively lower rate of decrement in the curves (Figure 7) displayed at post-peak stage compared to those exhibited in pre-peak stage is another indication for the mid-phase which develops between elastic and plastic stages under tensile elongation of the fibers. As such, although the tensile stress arrives to peak within $1 \%$ of longitudinal elongation, drops off from the peak and reaches to plastic stage by undergoing 39\% of additional elongation after the peak (Figure 7). Further, the asymptotic behaviors observed in the curves in Figure 7 at which the stress to strain ratio remains almost constant after $40 \%$ of tensile elongation until the rupture of the fiber at about $100 \%$ elongation point out the occurrence of plastic deformation where inconsequential change is seen in tensile stress with increasing axial strain throughout an interval of significant amount of elongation prior to fiber break. Consequently, three distinct parts, within the entire range of ambient test temperatures, are seen in tensile force versus elongation response of the micro-fibers including a 
predominant plastic stage occurred during or mobilized over $60 \%$ fraction of the total axial elongation developed in the fibers under tension, verifying that the micro-fibers are capable of withstanding greater extent of plastic elongation. This denotes that a ductile response with a predominant plastic phase has been observed for tensile stress versus strain behavior of the micro-PP-fibers regardless of ambient temperature tested. Additionally, as the temperature increases, the amount of plastic axial elongation exhibited by the micro-fibers becomes larger. This is associated with material hardness as the polymeric micro-fibers inherently become softer, and hence, more ductile when ambient temperature increases resulting in greater flexibleness.

Moreover, as compared to the warmer test temperatures above $0{ }^{\circ} \mathrm{C}$, there occurs a slight variation in the values of tensile stresses measured in the different replicate tests at the same ambient conditions for the micro-fibers particularly when the ambient test temperature becomes colder much below $0{ }^{\circ} \mathrm{C}$. This is associated with the inherent material properties of polymeric PP-fibers such that the firmness of the micro-fibers as per micro-mechanical stability in exhibiting identical tensile strength response in the replicate tests at the same ambient conditions becomes less consistent with a further decrease in ambient temperature especially below $0{ }^{\circ} \mathrm{C}$ (Figures 6 and 7).

\subsection{Fiber Micro-Mechanical Properties and Stages of Force-Displacement Failure Envelopes}

Tensile stress versus strain/stress curves at different temperatures presented in Figure 6 clearly illustrated different stages of elasto-plastic behavior and yielding stages of the tested micro-fibers in demonstrating the mechanisms for the transformation of the tensile behavior from elastic to plastic passing through the two yielding stages including initial and ultimate yielding of the fibers under tensile elongation. In this perspective, Figure 8 presents the mean tensile stress versus strain/stress curves as a function of the temperature starting from the standard room temperature of $21^{\circ} \mathrm{C}$ down to the ambient cold temperature condition of $-10^{\circ} \mathrm{C}$. These mean curves are descriptive in emphasizing that the micro-fibers resulted in a similar trend of tensile stress versus axial strain response at all test temperatures such that the tensile stress - strain/stress curves have a nonlinear elasto-perfectly-plastic form regardless of the ambient temperature tested. The mean curves shown in Figure 8 provided an opportunity in illustration for a detailed view and helping to see clearly the different stages of elasto-perfectly-plastic behavior and fiber yielding stage in depicting the details of transformation of the behavior from elastic to plastic. Additionally, the curves demonstrate that there occurs a dramatic, very sharp increase in tensile stress within a small strain of the fiber, and thereafter, the rate of increase in tensile stress becomes gradual at a slower rate prior to yielding, and thus, transforming to plastic response after elastic elongation. 


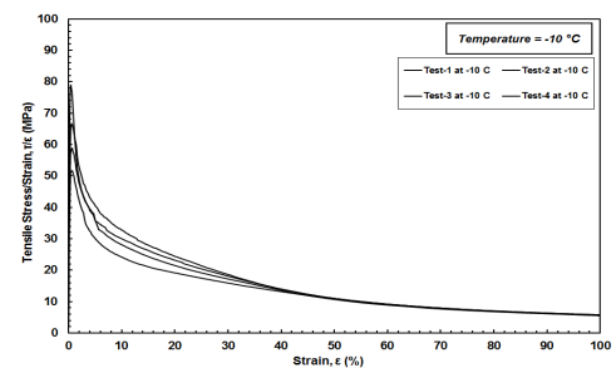

(a)

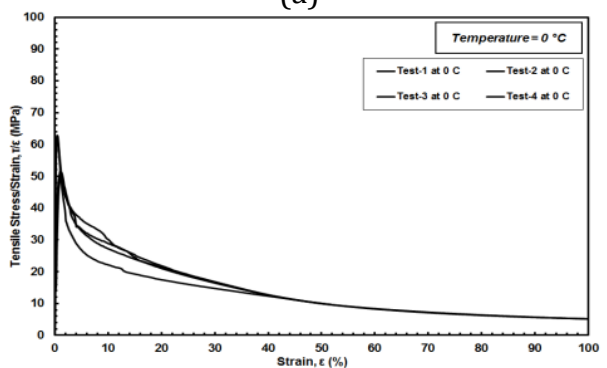

(c)

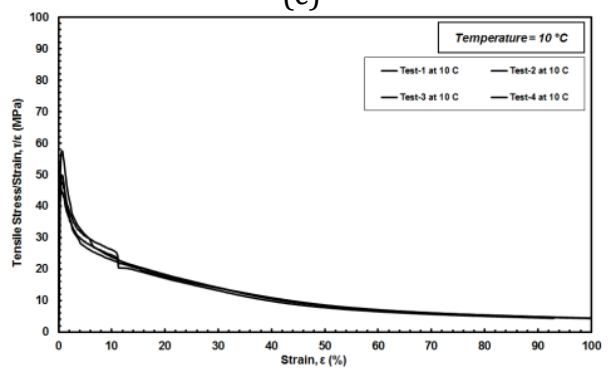

(e)

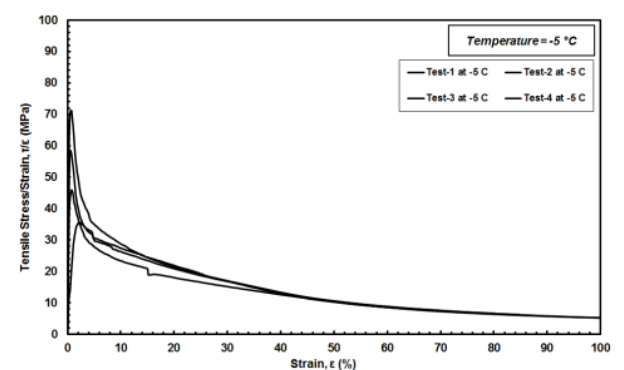

(b)

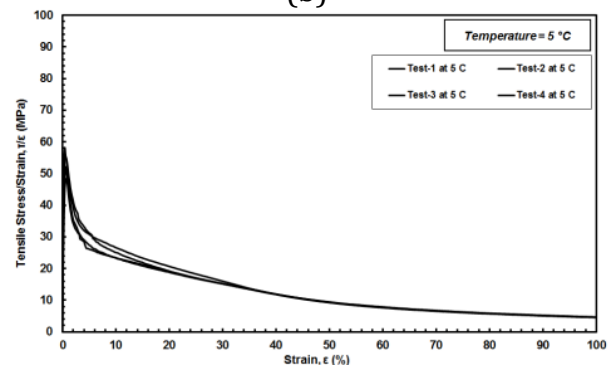

(d)

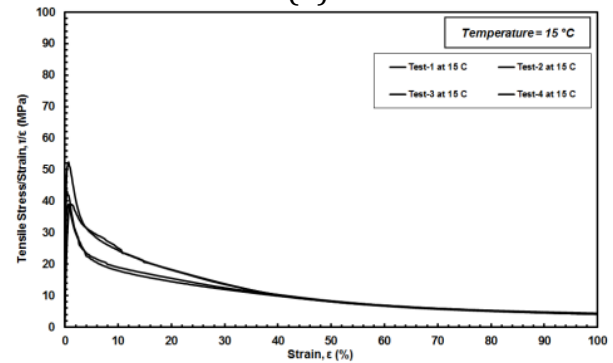

(f)

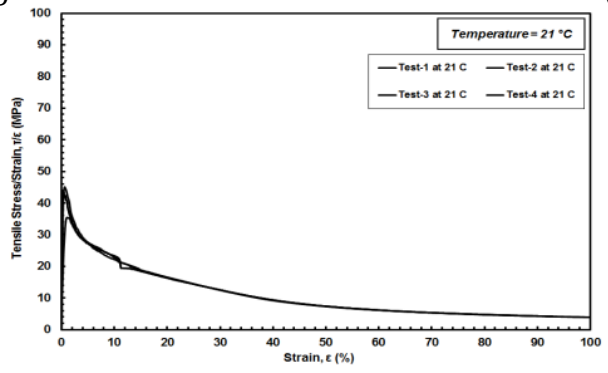

(g)

Fig. 7 Assessment of Ductility and Brittleness for Tensile Elongation Response of the PP Micro-Fibers

As demonstrated in Figure 8, the general pattern in tensile stress -strain/stress behavior of polypropylene fibers in the tension tests at different ambient cold temperatures ranging from $21^{\circ} \mathrm{C}$ down to $-10{ }^{\circ} \mathrm{C}$ can visually be portrayed in three segments: i) strain/stress ratios start about $0.05 \mathrm{MPa}^{-1}$ and proceed to left on the graph space with a steady rise at a very low (minimal) slope, and thereafter, the curves undergo initial yielding at a strain over stress ratio of $0.015 \mathrm{MPa}^{-1}$ as well as they change direction by progressing to slightly right on the graph space, and then; ii) tensile stress increases dramatically within a relatively 
small range of $0.04 \mathrm{MPa}^{-1}$ strain over stress ratio, and finally; iii) the curves exhibit ultimate yielding stage and level off, remains more or less constant at greater strain over stress ratios displaying perfectly-plastic response with a nearly constant resistances after ultimate yielding stage prior to fiber rupture. Moreover, the curves at all test temperatures reached rupture failure at axial elongations from $100 \%$ to $120 \%$. Consequently, it is noted that a transition dominant tensile behavior (Figures 6 and 8) was observed for the PPmicro-fibers at colder temperatures than the room temperature $\left(\leq 21{ }^{\circ} \mathrm{C}\right)$ including; i) elastic stage developing from initiation of the test up to initial yielding, ii) elastic stage continuing and displaying a gradual decrease in the rate of increase in tensile stress with increasing strain from initial yielding to ultimate yielding, iii) plastic stage mobilizing after ultimate yielding until fiber rupture being the predominant mechanism for the examined tensile response of the micro-fibers over the entire test temperatures ranging from $-10{ }^{\circ} \mathrm{C}$ to $21^{\circ} \mathrm{C}$. In summary, the uniaxial tensile stress versus axial strain behavior of the fibers at different ambient temperatures tested consists of elastic straining, transition zone and predominant plastic deformation (Figure 8). That is to say, tensile stress ramps up dramatically within very small axial extensional displacements at a range of $0.04 \mathrm{MPa}^{-1}$ strain over stress ratio, and then, it remains almost constant during inelastic deformation of the polymeric material after passing through yielding deformation. The inelastic portions of the stress versus strain/stress curves are essentially parallel at all test temperatures.

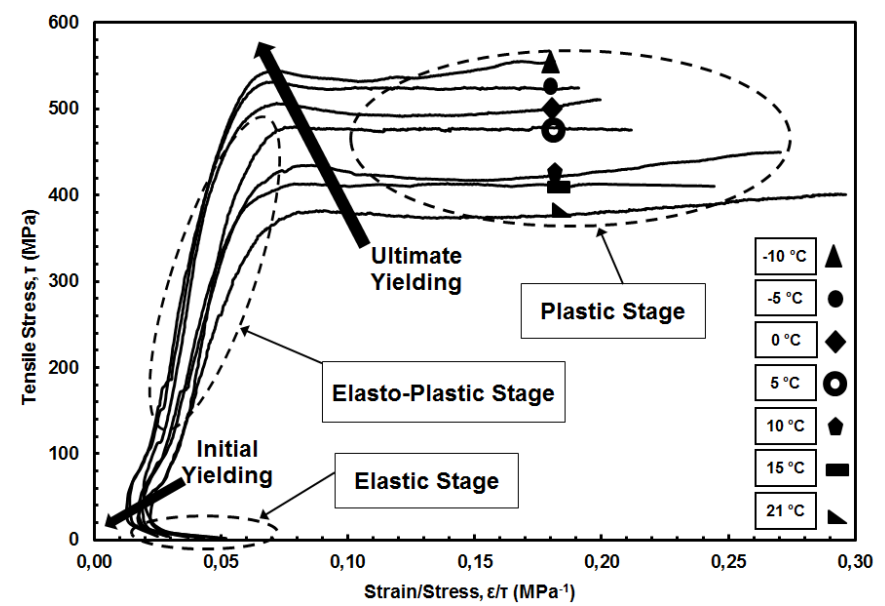

Fig. 8 Different Phases of Elasto-Perfectly-Plastic Behavior and Fiber Yielding Stage

To sum up, as evident from Figures 5 through 8, the force - displacement curves underwent a relatively short elastic deformation stage as compared to a longer plastic deformation phase. As such, all the micro-fiber specimens tested experienced greater amount of strains prior to failure by proceeding through all three main phases of elastoplastic deformation including elastic, yielding and plastic zones. In this perspective as per the polymer material properties of the micro-fibers, the tensile force versus axial elongation behavior, in principle, can be divided into three separate zones, depending on the molecular response of the polymer to the level of applied strain [6-8]; i) Within Zone $\mathrm{I}$, the response to load is instantaneous and elastic, since the deformations are recoverable upon load removal; ii) Deformations within Zone II are still recoverable, but not instantaneously. Time dependent response within Zone II usually is generally associated with visco-elastic behavior; iii) Within Zone III, the material exhibits an inelastic response 
in that the deformations are irrecoverable upon load removal and response within this region is related to plastic behavior in which strains consist plastic components. In terms of physico-chemical considerations, the stretching of inter-atomic bonds occurs in Zone I when going through elastic elongation. Throughout the transition zone (Zone II), polymer molecular chains get straightened. Lastly, the relative displacement of molecules in the polymer takes place in Zone III during plastic deformation.

\subsection{Modulus of Elasticity, $E$}

The observed tensile stress versus axial strain behavior of PP fiber specimens indicated that the fibers become stronger and stiffer as temperature decreases under the application of tensile load. The initial elastic portion of stress - strain curves rotates "counterclockwise" demonstrating an increase in stiffness; hence, elasticity modulus with decreasing temperature. As such, the result of micro-scale tensile tests on the PP fibers disclosed and presented that the modulus of elasticity increased at an increasing rate incrementally as the ambient temperature decreased. Figure 9a shows the change of elasticity modulus as a function of temperature. The values of the modulus of elasticity have been calculated from initial linear portions of the stress versus strain curves. The mean diameter of a single fiber under zero tensile load is $35 \mu \mathrm{m}(0.035 \mathrm{~mm})$ which constitutes an average cross sectional area of $9.62 \times 10^{-10} \mathrm{~m}^{2}\left(9.62 \times 10^{-4} \mathrm{~mm}^{2}\right)$. When the measured tensile forces on the order of 35 to 55 gram-force at various temperatures are divided by the small cross-sectional area of the fiber; then, the resulting elasticity modulus values were in the order of tens of MPa.

It is evident from Figure 9a that the PP fiber modulus is inversely proportional to temperature. The maximum stiffness for all the tests conducted in this study was obtained at the lowest ambient temperature $\left(-10^{\circ} \mathrm{C}\right)$. As such, the fibers produced from polymers were stiffer and firmer at colder temperature conditions and became relaxed and more flexible at warmer temperatures such as the room temperature $\left(21^{\circ} \mathrm{C}\right)$. Consequently, in the tests at lower temperatures, the fibers underwent less deformation as compared to those of at higher ambient temperatures before proceeding through transition deformations or yielding from elastic type to plastic type elongations. A regression analysis performed on the experimental data based on second-order polynomial fit provided a good quadratic increase model with a high "coefficient of determination" of 0.9815 . The closeness of fit between the regression curve and the test data indicates that a good correlation between the temperature and the modulus of the fibers exists (Figure 9a). The empirical relationship (Equation 1) between fiber modulus and temperature was developed based on the results of micro-scale tensile tests at different ambient temperatures and could be utilized as a mathematical empirical relationship to relate elasticity modulus to temperature change in which Young's modulus values follow a nonlinear pattern with decreasing temperature for the PP fibers extracted from NPNW geotextiles.

$$
E(M P a)=0.0396 x\left[T\left({ }^{\circ} \mathrm{C}\right)\right]^{2}-1.5724 x\left[T\left({ }^{\circ} \mathrm{C}\right)\right]+49.752
$$

where, E : Modulus of elasticity (MPa), T: Temperature $\left({ }^{\circ} \mathrm{C}\right)$

\subsection{Modulus of Resilience, $U_{R}$}

Resilience is defined as the ability of a material to absorb energy when deformed elastically, and release that energy upon unloading [6, 7, 14, and 15]. As seen from the results of experimental program at different cold temperature conditions, tensile stress versus axial strain curves had a similar form with a sharp increase prior to arriving in the transition zone and ultimately experiencing plastic deformation at all temperatures tested 
(Figure 5). In light of this, resilience for the fibers can be determined based on the concept of being the maximum energy that they absorb under tension within the elastic limit without creating a permanent distortion before the transition zone (yielding stage) of stress - strain curves. Therefore, the modulus of resilience for the PP fibers tested at various temperatures was calculated by integrating tensile stress with respect to axial strain - that is basically the area underneath of the stress - strain curves - from zero up to the elastic limit so as to obtain the elastic deformation energy per volume of the test specimen, referring to resilience, until at a point where the first departure from linearity occurs. In terms of physical considerations, the elastic deformation energy under tensile elongation per volume of the test specimen describing the modulus of resilience is basically observed during elastic straining wherein the developed deformations are instantaneously recoverable. The modulus of resilience $\left(U_{R}\right)$ for the PP fibers increased exponentially as the ambient temperature decreased (Figure 9b). It means that the area under tensile stress versus axial strain curves until elastic limit, that is the elastic deformation energy per volume of test specimen, enlarges with an increasing rate with decreasing temperature. The modulus of resilience was smallest at room temperature $\left(21^{\circ} \mathrm{C}\right)$ and displayed an increase at colder temperatures $\left(<21^{\circ} \mathrm{C}\right)$. As such, the maximum energy required and absorbed per unit volume of the PP fibers without creating a permanent plastic deformation (elongation) becomes greater with a decrease in the ambient temperature.

Moreover, the rate of increase for the modulus of resilience $\left(U_{R}\right)$ became greater over the range of ambient temperatures particularly between $5{ }^{\circ} \mathrm{C}$ and $-10{ }^{\circ} \mathrm{C}$ as compared to that of the range of ambient temperatures between $20^{\circ} \mathrm{C}$ and $5^{\circ} \mathrm{C}$. As such, the $U_{R}$ displays an increase at a lower rate from $20^{\circ} \mathrm{C}$ down to $5{ }^{\circ} \mathrm{C}$, whereas the $\mathrm{U}_{\mathrm{R}}$ exhibits a raise at a higher rate from $5{ }^{\circ} \mathrm{C}$ down to $-10^{\circ} \mathrm{C}$. Besides, the exponential model developed provides a higher coefficient of determination value $\left(\mathrm{R}^{2}\right)$ in comparison to that of the linear regression fit. For this reason, the exponential model obtained has been thought of a better regression fit both in precisely displaying the overall behavior (the change or variation of $U_{R}$ with decreasing temperature) and in accurately demonstrating a closer proximity between intermittent test data and continuous regression curve that resulted in attaining a larger value of $\mathrm{R}^{2}$ closer to 1 . To this end, the obtained empirical relationship between modulus of resilience and temperature (exponentially increasing behavior of $U_{R}$ as a function of temperature) is given in Equation $2(\mathrm{CoD}=0.9832)$ :

$$
U_{R}\left(J / m^{3}\right)=\left(1 \times 10^{8}\right) x e^{-0.018 x\left[T\left({ }^{\circ} \mathrm{C}\right)\right]}
$$

where, $\mathrm{U}_{\mathrm{R}}$ : Modulus of resilience $\left(\mathrm{J} / \mathrm{m}^{3}\right), \mathrm{T}$ : Temperature $\left({ }^{\circ} \mathrm{C}\right)$ 


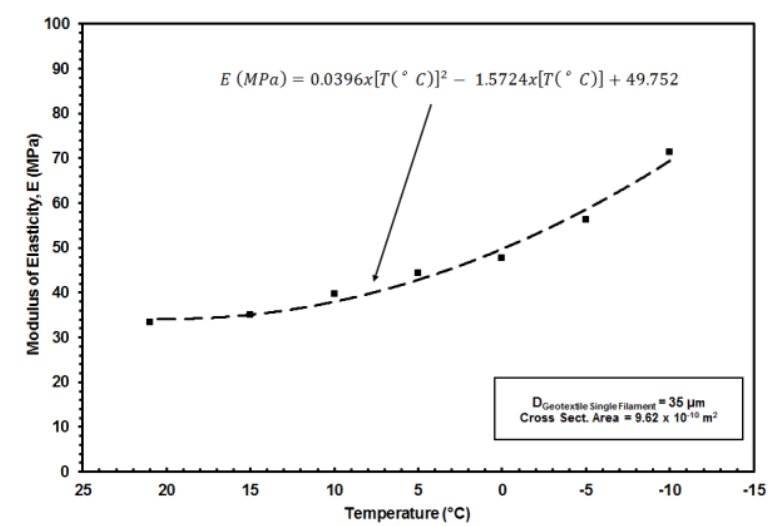

(a)

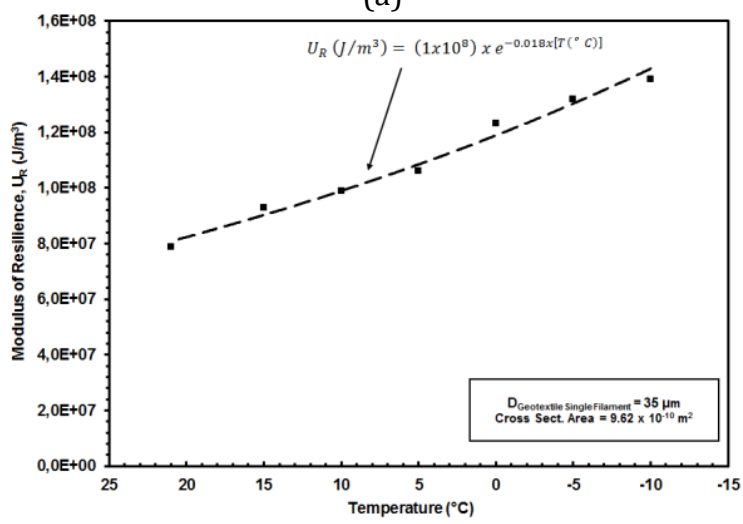

(b)

Fig. 9 Elastic Stage Mechanical Properties of the Micro-Fibers and Temperature:

(a) Modulus of Elasticity (E); (b) Modulus of Resilience ( $U_{R}$ )

\subsection{Tensile Strength, $\tau_{\max }$}

One of the most important mechanical properties of polymeric materials is its tensile strength under tensional elongation that shows indestructibility of the material employed in the field. Since a polymer type (PP) is used as a base material to produce geotextile micro-fibers, they do not maintain and sustain tensile strength and robustness properties with temperature change to which most geotechnical engineering applications are exposed. It was observed as a result of micro-scale tensile tests on the PP micro-fibers that tensile strength, $\left(T_{\max }\right)$ increased as the ambient temperature decreased with greater tensile strength under tension measured at lower cold temperature conditions (Figure $10 \mathrm{a}$ ). The resulting values of tensile strength measured were on the order of hundreds of $\mathrm{MPa}$. The PP micro-fibers at cold temperatures were stronger and resistant but became weaker and less strong at higher warm temperatures due to polymer material properties changing with temperature and the bonding strength of polypropylene molecules strongly dependent on the ambient temperature conditions. However, this is only the micro-level response of the fibers extracted from a geotextile fabric. At global state (macro-level), depending on fiber processing type and fabric manufacturing method, temperature might have minor influence on tensile properties of geotextile fabric sheet [11-13] due to internal structural formation which is generated through fiber-fiber interlocking (bonding), nature of inner voids, and ability of fibers for rearrangement under external forces. 
As seen from Figure 10a, there is an inverse proportion in between tensile strength of the PP micro-fibers and temperature in which they possess higher tensile strength values at lower temperatures due to more intact chemical composition and stronger bonding type of base polymer molecules (polypropylene) of the fiber at cooler temperatures resulting from the material physico-chemical properties. Further, several different types of regression analysis such as linear, exponential, polynomial were performed on the micromechanical tensile test data. The linear regression provided the best correlation between tensile strength and temperature such that a very good fit between intermittent test data and continuous regression curve for which a higher coefficient of determination (CoD) of 0.9807 was obtained as compared to that of polynomial or exponential regression models that resulted in lower CoD values. For single PP fibers extracted from NPNW geotextile and stretched axially (elongation) under tensile force at micro-state at several temperatures, the empirical relationship developed through regression analysis of micro-tensile test data to relate the change in tensile strength to the variation in ambient temperature is given as follows:

$$
\mathrm{T}_{\max }(M P a)=-5.3817 x\left[T\left({ }^{\circ} \mathrm{C}\right)\right]+503.27
$$

where, $\mathrm{T}_{\max }$ : Tensile strength $(\mathrm{MPa}), \mathrm{T}$ : Temperature $\left({ }^{\circ} \mathrm{C}\right)$

\subsection{Rupture Strength, $\tau_{R}$}

The tensile stress versus axial strain curves showing force versus elongation response of the micro-fibers, regardless of ambient temperature tested, underwent a relatively short elastic deformation stage as compared to a much longer plastic deformation phase (Figures 5 and 8). That is to say, almost all the fiber specimens experienced larger strains (axial elongations) prior to failure by progressing through all three main phases including elastic stage, transition zone, and plastic deformation (Figure 8), typical for elasto-plastic behavior, prior to exhibiting failure (break) that is called the rupture of the PP micro-fibers under tensional elongation. In the micro-scale tensile tests at various temperatures, the tensile force increased rapidly in a very sharp manner within very small axial strains during elastic stage, then, it remains almost constant during inelastic and irrecoverable deformation of the polymeric material after passing through yielding stage, consequently resulted in inelastic portions of the stress-strain curves being essentially parallel (Figures 5 and 6). This shows that the sturdiness of the PP fibers maintained and sustained more or less same with a minor trivial strength loss after experiencing maximum tensile stress (tensile strength) as tensile elongation continued to larger axial strains. Similar to the tensile strength $\left(T_{\max }\right)$ that increased with decreasing temperature, the rupture strength $\left(T_{R}\right)$ increased with a decrease in temperature such that the higher rupture strength under tensional elongation has been measured at lower cold temperature conditions (Figure 10b).

A linearly increasing behavior was observed for which the empirical relationship attained based on the regression of intermittent experimental data is given in Equation 4 for the rupture strength $\left(T_{R}\right)$ as a function of temperature. A high coefficient of determination (CoD $=0.9836$ ) obtained from the regression analysis in between the discontinuous test data and the resulting continuous regression line shows that the best correlation between rupture strength $\left(T_{R}\right)$ and temperature with a very good fit is the linear ( $1^{\text {st }}$ order$)$ relationship as follows:

$$
\mathrm{T}_{R}(M P a)=-5.2581 x\left[T\left({ }^{\circ} \mathrm{C}\right)\right]+502.11
$$

where, $\mathrm{T}_{\mathrm{R}}$ : Rupture strength (MPa), T : Temperature $\left({ }^{\circ} \mathrm{C}\right)$ 
Furthermore, Figure 10a presents the change of mean tensile strength - that is the average of the maximum tensile stress measured at every four replicate tests at each test temperature - with a variation in the ambient temperature. On the other hand, Figure $10 \mathrm{~b}$ shows the change of mean rupture strength - that is the average of the tensile stress at failure or break of the micro-fibers measured at every four replicate tests at each test temperature - with a variation in the ambient temperature. Since, at each ambient temperature, the four replicate tests were performed to demonstrate similar response and consistent behavior which confirms the reproducibility of the tensile strength of the PP micro-fiber at every test temperature and the repeatability of the developed tensile stress - axial strain behavior for the tested fibers at micro-state. Furthermore, Figure 10b verifies that the PP micro-fibers exhibited elastic-perfectly-plastic response over the entire range of test temperatures as the tensile strength measured was very similar to the rupture strength at break at every micro-tensile tests. The onset of plastic deformation has been determined by analyzing the experimental data after ultimate yielding (Figure 8) in the tests based on variation in the measured values of tensile stress for the condition being within 5 percentile ( $5 \%$ ). Figures 6 and 8 were generated, accordingly, on this purpose to demonstrate a better illustration and definite borders in the plots between different test stages including elastic, elasto-plastic and plastic.

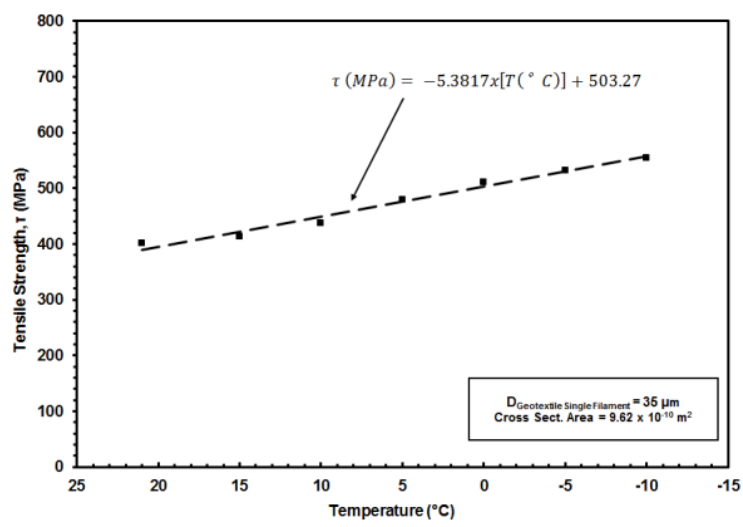

(a)

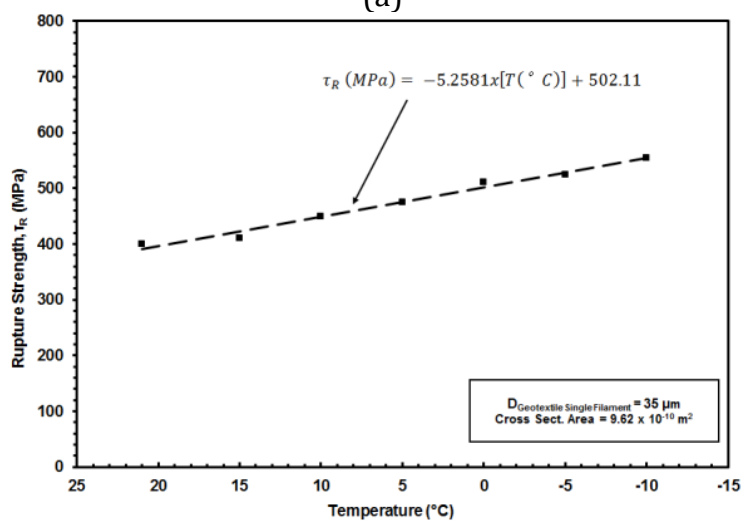

(b)

Fig. 10 Tensile and Rupture Strength of the Micro-Fibers and Temperature:

(a) Tensile Strength ( $\left.\tau_{\max }\right)$; (b) Rupture Strength $\left(\tau_{R}\right)$ 


\subsection{Amount of Plastic Strain, $\varepsilon_{p}$}

The PP micro-fibers exhibited higher values of modulus of resilience at colder temperature conditions while they displayed lower strains prior to yielding until elastic limit as well as, most importantly, lower extent of plastic strains $\left(\varepsilon_{\mathrm{p}}\right)$ before the rupture. This is attributed to the improvement of the stiffness properties of polymeric fiber with a decrease in the ambient temperature. Figure 11 a shows the change in the value of plastic strain $\left(\varepsilon_{p}\right)$ as a function of temperature. The polymeric fiber became more brittle and its capacity to sustain plastic deformation under tension diminished and experienced less permanent strains or plastic deformations by encountering the rupture - that is the occurrence of failure - at smaller tensile elongations at colder temperature conditions. A linearly decreasing behavior was observed for the plastic strain $\left(\varepsilon_{\mathrm{p}}\right)$ exhibited by the polymericmicro-fibers in the tests with a decrease in the ambient temperature. The empirical relationship obtained for the plastic strain as a function of temperature is given in Equation 5 with a high value of coefficient of determination $(\mathrm{CoD}=0.9932)$ :

$$
\varepsilon_{p}(\%)=0.21 x\left[T\left({ }^{\circ} \mathrm{C}\right)\right]+64.88
$$

where, $\varepsilon_{\mathrm{p}}$ : Amount of plastic strain $(\%), \mathrm{T}$ : Temperature $\left({ }^{\circ} \mathrm{C}\right)$

\subsection{Toughness, $U_{T}$}

Toughness can be defined as the ability of a material to absorb energy and experience full range of deformation both elastically and plastically during tensional elongation without rupturing $[3,7,8]$. Therefore, toughness, in physical meaning, can describe the amount of total energy per unit volume that a material can absorb before rupturing, and hence, toughness can be a proper measure for a polymeric material (PP micro-fiber) at what degree (severity) it shows a resistance against rupture when stressed. As such, toughness requires a balance of strength and ductility such that a material should be capable of withstanding both high stresses and high strains. The PP micro-fibers are highly ductile with the majority of the tested fibers experiencing a large amount of plastic deformation before the failure (breaking). For example, some of the fibers were able to elongate up to a maximum strain of more than $120 \%$ that resulted in a high energy absorption level. This is attributed to greater toughness properties of the micro-fibers signifying how much energy capacity they have to absorb before rupturing that is relevant to durability and long-term performance, while their strength implies only how much load resistance capacity they have to support and sustain over lifetime prior to failure. Further, the energy ingested (consumed) until rupture (toughness) under tensile force and elongation is essentially irreversible due to typical nature of the force-elongation behavior of the microfibers being predominantly plastic as opposed to resilience for which the energy absorbed is reversible such that the energy is released back upon unloading the material.

For the tested PP micro-fibers at different ambient temperatures, toughness $\left(\mathrm{U}_{\mathrm{T}}\right)$ was determined by integrating the area under the stress-strain curves so as to find the total energy of mechanical deformation, including elastic, elasto-plastic and plastic, per unit volume under tensile elongation up to the point of failure that will extend the understanding for the ability of the PP fibers at cold temperature conditions in absorbing mechanical energy. Toughness for the micro-fibers increased linearly with decreasing temperature (Figure 11b). This verifies that the area under the tensile stress versus axial strain curve enlarges with a decrease in the ambient temperature. Among several different types of regression analyses such as linear, exponential, polynomial performed on the computed values of toughness at different temperatures, the linear regression provided the best correlation between toughness and temperature with a higher coefficient of 
determination (CoD) of 0.9839 much closer to 1 (Figure $11 \mathrm{~b}$ ). Therefore, it is noted that tensile toughness for the PP micro-fibers is a function of ambient temperature such that the energy absorbed per unit volume of the fibers rises when the ambient temperature becomes colder. The resulted empirical relationship (Equation 6) between toughness and temperatures is as follows:

$$
U_{T}\left(J / m^{3}\right)=-5 \times 10^{6}\left[T\left({ }^{\circ} \mathrm{C}\right)\right]+4 \times 10^{8}
$$

where, $\mathrm{U}_{\mathrm{T}}$ : Toughness $\left(\mathrm{J} / \mathrm{m}^{3}\right), \mathrm{T}$ : Temperature $\left({ }^{\circ} \mathrm{C}\right)$

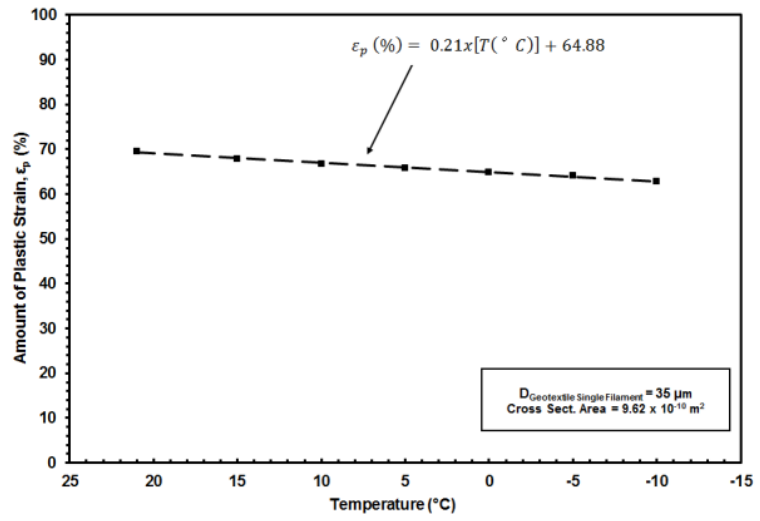

(a)

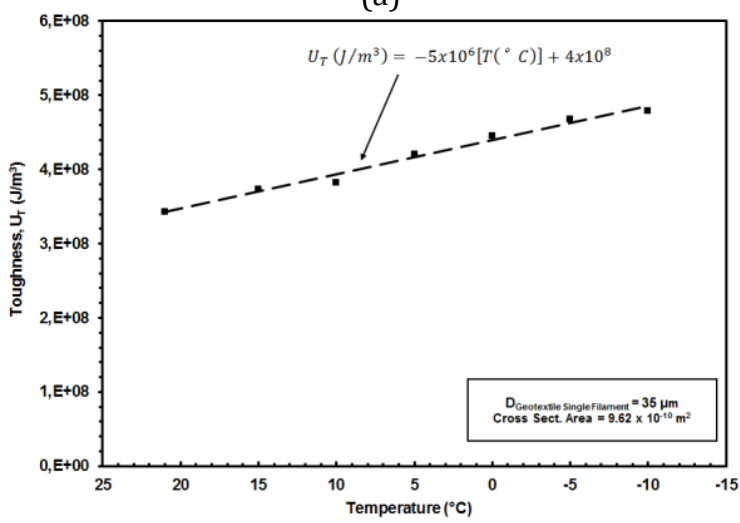

(b)

Fig. 11 Plastic Stage Mechanical Properties of the Micro-Fibers and Temperature:

(a) Amount of Plastic Strain $\left(\varepsilon_{\mathrm{p}}\right)$; (b) Toughness $\left(\mathrm{U}_{\mathrm{T}}\right)$

\section{Further Discussion on Experimental Findings}

Based on the experimental findings of the study, the micro-mechanical properties of the PP fibers do not remain constant within the range of cold temperatures $\left(-10{ }^{\circ} \mathrm{C}<\mathrm{T}<20\right.$ ${ }^{\circ} \mathrm{C}$ ) encountered in typical infrastructural applications such that the ambient temperature change was found to be an important factor in affecting the polymeric fiber mechanical properties such as modulus, strength, toughness, ductility and most importantly, elastic (reversible) and plastic (irreversible) energy absorption of the micro-fibers under tensile elongation and their variation with ambient temperature. The amount of elastic energy absorption relative to the total magnitude of energy absorption (including elastic and 
plastic) for the PP micro-fibers under tensile loading increases with decreasing temperature (Figure 12). This is attributed to the polymer characteristics of micro-fibers such that the resilience of the PP fibers at micro-state enhances as a result of a decrease in the ambient temperature. As such, the micro-fibers were able to absorb more energy while loaded under tensile elongation within the elastic limit without creating a permanent yielding before the transition zone - that is the elastic-to-plastic transformation - prior to exhibiting permanent deformations in plastic nature as seen from the stress versus strain envelopes (curves). As such, the amount of reversible energy during elastic elongation of the fibers under tensile force becomes greater as temperature decreases (Figure 12a) and this is associated with elastic properties of the PP micro-fibers becoming intensified (improved) at lower temperatures.

Moreover, the amount of plastic energy absorption relative to the total magnitude of energy absorbed by the micro-fibers prior to rupture (break) under tensile elongation decreases with decreasing ambient temperature (Figure 12b). This shows that the PP fibers become less ductile and losing from their flexibility properties at colder temperatures resulting in observing ruptures - that is fiber breakage - at smaller elongations (i.e. strains) when subjected to tensile loads. This could influence the durability properties of the fibers, and hence, the survivability and longevity properties of the geotextile fabric sheets made from the PP micro-fibers tested in the study when employed in the field for infrastructural applications exposed to cold temperature conditions. Furthermore, the capacity of a material in terms of the capability for plastic energy absorption is associated with its compliance properties, whereas, the ability of a polymeric material regarding elastic energy absorption is related to its resilience properties. Therefore, the ductility versus brittleness properties of the PP micro-fibers such as their characteristics being ductile or brittle is strongly ambient temperature dependent at micro-state in light of the experimental findings (Figures 12a and 12b).

Figure $12 \mathrm{c}$ shows that the ratio of plastic energy absorption with respect to elastic energy absorption decreases as the ambient temperature decreases from $21^{\circ} \mathrm{C}$ down to $-10^{\circ} \mathrm{C}$. In this perspective, it is noted that the PP micro-fibers become more resilient but less compliant due to a decrease in the ambient environmental temperature that should be considered by the design engineers in assessing the mechanical and durability properties of the geotextile fabrics at different ambient temperatures that is produced from these PP micro-fibers when employed in the infrastructural facilities subjected to varied environmental conditions including temperature. Additionally, the fiber strength can be considered as the major factor controlling geotextile micro-scale mechanical properties, and hence, its macro-scale mechanical response such as tensile strength being the primary function of a geotextile fabric sheets utilized in the civil engineering applications. To this end, the global ("macro-scale") tensile response of nonwoven geotextiles, due to their fibrous inherent characteristics, is the summation of elastic elongations, inelastic (plastic) deformations in the micro-fibers as well as deformations due to the rearrangement of inherent internal structure including void space [12] which is not sensitive to temperature change $[11,13]$ in contrast to the elasto-plastic deformations of the polymeric micro-fibers under stress which is highly sensitive to the changes in the ambient conditions such as temperature as presented in the paper from the results of experimental program at microstate. Therefore, a contradictory response was observed for the micro-fibers extracted from geotextile fabric sheets when tested at the "micro-scale" level - reported in the paper - as opposed to the response inferred from tests at the "macro-scale" level - published earlier by Andrawes et al. [11]. This primarily results from fibrous geotextile inherent characteristics having different "micro-structure" and "macro-structure" properties.

Moreover, the sudden change observed at a temperature of $0{ }^{\circ} \mathrm{C}$ to $5{ }^{\circ} \mathrm{C}$ is attributed to physico-chemical properties of the PP fibers such that the stretching of inter-atomic bonds 
occurs when going through elastic elongation becomes lower as temperature decreases below $0{ }^{\circ} \mathrm{C}$ resulting in polymer molecular chains getting less straightened. On the other hand, as temperature increases above $5{ }^{\circ} \mathrm{C}$, the relative displacement of molecules in the polymer takes place considerably during plastic deformation. For these reasons, there occurs a conversion in the behavior below $0{ }^{\circ} \mathrm{C}$ and above $5{ }^{\circ} \mathrm{C}$ such that at ambient temperatures particularly below $0{ }^{\circ} \mathrm{C}$, the ratio of elastic energy absorption with respect to total energy absorption prior to rupture gets higher suddenly. On the other hand, at ambient temperatures particularly above $5{ }^{\circ} \mathrm{C}$, the ratio of plastic energy absorption with respect to total energy absorption prior to rupture gets higher instantly.

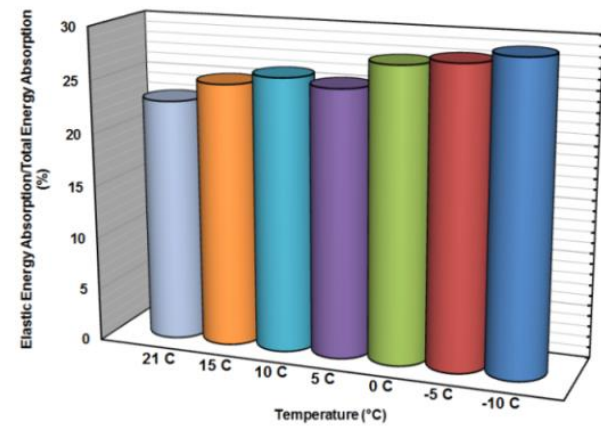

(a)

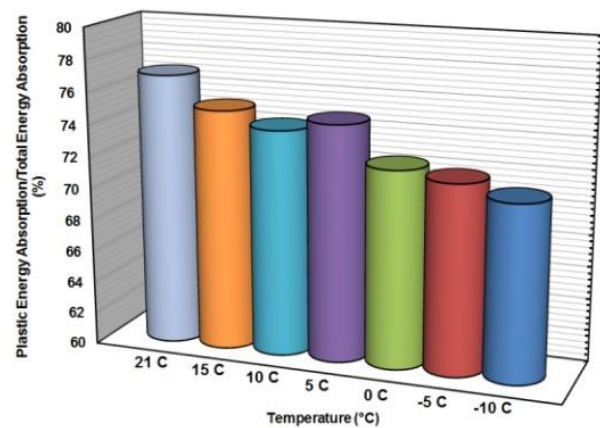

(b)

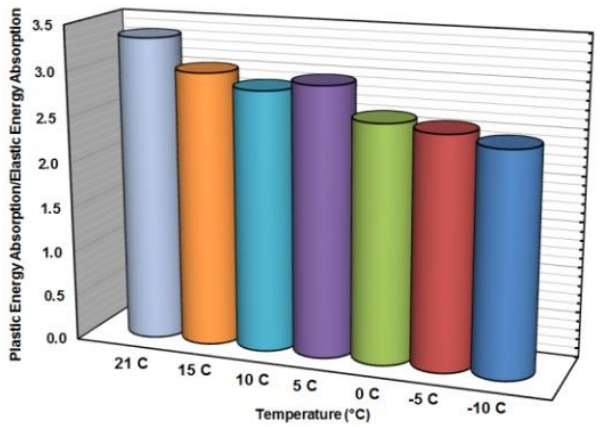

(c)

Fig. 12 Comparison of Elastic and Plastic Energy Absorption of the Micro-Fibers and their Variation with Ambient Temperature: (a) Elastic/Total (\%) vs. Temperature; (b) Plastic/Total (\%) vs. Temperature; (c) Plastic/Elastic vs. Temperature

\section{Conclusions}

The micro-fibers are used to manufacture nonwoven geotextile fabrics. Despite this fact, the previous studies were generally interested in mechanical and durability properties of geotextile fabrics at macro-state (global-scale). However, this study has been intended to provide unique as well as innovative aspect and carried out particularly for investigating the micro-mechanical properties of the fibers at micro-state and exploring the experimental methodology for their extensive characterization in the laboratory. In light of the information and the supplementary discussions provided throughout the paper regarding the influence of mechanical properties of the polymeric micro-fibers on the observed temperature dependent tensile stress versus axial strain behavior, the micromechanical response of the PP fibers were characterized by performing micro-scale mechanical tensile tests for which the testing method was adapted to a specialized 
computer automated dynamic mechanical system called DMA. The results of the experimental program were used to determine the modulus of elasticity (E), modulus of resilience $\left(U_{R}\right)$, ultimate tensile strength $\left(T_{\max }\right)$, amount of plastic strain $\left(\varepsilon_{\mathrm{p}}\right)$, toughness $\left(U_{T}\right)$, rupture strength $\left(T_{R}\right)$ for the PP fibers extracted from NPNW geotextiles, and additionally, to investigate the variation of those important mechanical properties for a polymeric fiber with a decrease in the ambient temperature. Various test temperatures between $-10^{\circ} \mathrm{C}$ and $21^{\circ} \mathrm{C}$ were chosen to simulate the cold temperature range expected in the field for infrastructural applications in which the geotextile fabric sheets produced from the PP micro-fibers are employed.

The major impacts of cold temperatures on micro-mechanical properties of the polymeric fibers were the enhancement in ultimate tensile strength and the increase in material stiffness - due to molecular bonding strength of polymeric fibers - which resulted in the increment of amount of total energy absorbed (toughness) prior to rupture (failure) under tensile elongations. As such, the instantaneous temperature-dependent modulus for the range of test temperatures such as typical of geotechnical practice increased in a quadratic form showing that the PP micro-fibers at cooler temperatures are stiffer than that of at warmer ambient temperatures. Further, the enhancement of the PP fiber stiffness with decreasing temperature is attributed to the polymer material properties such that the polymeric fiber becomes harder and its capacity to sustain plastic deformation under tension is improved. The change in those mechanical properties of the PP micro-fibers is a function of ambient temperature variation.

The PP fiber specimens experienced the same failure mode such that they exhibited significant ductility under tensile elongation within the entire range of test temperatures from $-10{ }^{\circ} \mathrm{C}$ to $21^{\circ} \mathrm{C}$. Further, a similar trend for tensile stress versus axial strain response at all test temperatures was observed for the PP micro-fibers such that the tensile stress axial strain curves have a nonlinear elasto-perfectly plastic form. The general pattern in stress-strain response of polypropylene fibers in the tension tests was visually portrayed in two segments: i) sharp increase to a maximum; then, ii) leveling off at higher strain levels such that the micro-fibers exhibited nearly constant resistances after yielding until they reached rupture at elongations between $100 \%$ and $120 \%$ axial strains. The elastic portion of the curves, before experiencing yield, develops with a relatively constant rate of change in tensile stress with respect to axial strain. Additionally, the resulting tensile stress versus axial strain curves for lower temperature tests are located on the upper part of the stressstrain space compared with that of the higher temperature tests. This shows that the tension failure envelopes grew (enlarged) as the ambient temperature decreased

\section{References}

[1] Nielsen LE,.Mechanical properties of polymers and composites. Vol. 1, 2, Marcel Dekker Inc., NY, USA, 1974.

[2] Painter PC, Coleman MM. Fundamentals of polymer science. 2nd Edition, CRC press, Boca Raton, FL, USA, 1997.

[3] Zhai Z, Jiang B, Drummer D. "Temperature-dependent response of quasi-unidirectional E-glass fabric reinforced polypropylene composites under off-axis tensile loading," Composites Part B, Vol. 148, No. 4, 2018, pp. 180-187. https://doi.org/10.1016/j.compositesb.2018.04.058

[4] Li J-H, Hsieh J-C, Lou C-W, Hsieh,C-T, Pan Y-J, Hsing W-H, Lin J-H. "Needle punched thermally-bonded eco-friendly nonwoven geotextiles: Functional Properties," Materials Letters, Vol. 183, No. 6, 2016, pp. 77-80. https://doi.org/10.1016/j.matlet.2016.07.074 
[5] Mitchell JK, Seed RB, Seed HB. "Kettleman Hills Waste Landfill Slope Failure. I: Liner System Properties," Journal of Geotechnical Engineering, Vol. 116, No. 4, 1990, pp. 647 668. https://doi.org/10.1061/(ASCE)0733-9410(1990)116:4(647)

[6] Nielsen LE, Landel RF. Mechanical Properties of Polymers and Composites. Marcel Dekker, Inc., New York, NY, USA, 1994.

[7] Dowling NE. Mechanical behavior of materials. 3rd Edition, Pearson Prentice Hall, Upper Saddle River, NJ, USA, 2007, 912p.

[8] Youssefi M, Safaie B. "The study on the mechanical properties of multi-walled carbon nanotube/polypropylene fibers," Journal of Institution of Engineers, India Series E, Vol. 99, No. 1, 2018, pp. 37-42. https://doi.org/10.1007/s40034-017-0110-3

[9] Stein RS, Powers J. Topics in Polymer Physics. Imperial College Press, London, UK, 2006, 414p. https://doi.org/10.1142/p302

[10] Daniels C. Polymers: Structure and Properties. Technomic Publishing Company, Inc., Lancaster, PA, USA, 1989.

[11] Andrawes KZ, McGown A, Kabir Md. H. "Uniaxial Strength Testing of Woven and Nonwoven Geotextiles," Geotextiles and Geomembranes, Vol. 3, No. 1, 1984, pp. 41-56. https://doi.org/10.1016/0266-1144(84)90004-9

[12] Kobler J, Schneider M, Ospald F, Andra H, Muller R. "Fiber orientation interpolation for the multiscale analysis of short fiber reinforced composite parts," Computational Mechanics, Vol. 61, No. 4, 2018, pp. 729-750. https://doi.org/10.1007/s00466-0171478-0

[13] Kumar NS, Shabaridharan K, Perumalraj R, Ilango, V. "Study on cross directional tensile properties of bamboo-/polypropylene-blended needle-punched non-woven fabrics," Journal of Industrial Textiles, Vol. 47, No. 6, 2018, pp. 1342-1356. https://doi.org/10.1177/1528083717690611

[14] Osswald T, Menges G, Material Science of Polymers for Engineers. Hanser/Gardner Publications, Cincinnati, Ohio, USA, 1995.

[15] Lunenschloss J, Albrecht W. Non-Woven Bonded Fabrics. J. Translation editor: Hock, Ellis Horwood, 1985, 549p. 